\title{
High-resolution Fourier-transform ultraviolet-visible spectrometer for the measurement of atmospheric trace species: application to $\mathrm{OH}$
}

\author{
Richard P. Cageao, Jean-Francois Blavier, James P. McGuire, Yibo Jiang, Vassilii Nemtchinov, \\ Frank P. Mills, and Stanley P. Sander
}

\begin{abstract}
A compact, high-resolution Fourier-transform spectrometer for atmospheric near-ultraviolet spectroscopy has been installed at the Jet Propulsion Laboratory's Table Mountain Facility $\left(34.4^{\circ} \mathrm{N}, 117.7^{\circ} \mathrm{W}\right.$, elevation $2290 \mathrm{~m}$ ). This instrument is designed with an unapodized resolving power near 500,000 at 300 $\mathrm{nm}$ to provide high-resolution spectra from 290 to $675 \mathrm{~nm}$ for the quantification of column abundances of trace atmospheric species. The measurement technique used is spectral analysis of molecular absorptions of solar radiation. The instrument, accompanying systems designs, and results of the atmospheric hydroxyl column observations are described. (C) 2001 Optical Society of America
\end{abstract}

OCIS codes: $\quad 010.1280,120.0280,300.6300,300.6540$.

\section{Introduction}

Long-term measurements of transient species in the $\mathrm{HO}_{x}, \mathrm{NO}_{x}, \mathrm{CIO}_{x}$, and $\mathrm{BrO}_{x}$ families are important for the validation of models of stratospheric chemistry and transport and to verify that the phaseout of chlorofluorocarbons mandated by the Montreal Protocol is having the desired effect on stratospheric composition. The free radicals $\mathrm{OH}, \mathrm{NO}_{2}, \mathrm{NO}_{3}$, and $\mathrm{BrO}$ are key intermediates in catalytic ozone destruction cycles and are suitable candidates for detection by ground-based UV-visible spectroscopy. Of these species, the $\mathrm{OH}$ radical plays the most important role from the surface through the mesosphere.

A number of techniques have been employed to characterize the distribution of upper-atmospheric $\mathrm{OH}$ including in situ laser-induced fluorescence, ${ }^{1,2}$ far-infrared spectroscopy, ${ }^{3-6}$ and near-UV spectro-

R. P. Cageao (Richard.P.Cageao@jpl.nasa.gov), J.-F. Blavier, Y. Jiang, V. Nemtchinov, F. P. Mills, and S. P. Sander are with the Jet Propulsion Laboratory, California Institute of Technology, 4800 Oak Grove Drive, Pasadena, California 91109-8001. S. P. Sander is also associated with the Division of Geological and Planetary Sciences and the Division of Engineering and Applied Sciences, California Institute of Technology, Pasadena, California 91125. J. P. McGuire is with the Optical Research Corporation, 3280 East Foothill Boulevard, Pasadena, California 91107.

Received 20 March 2000; revised manuscript received 17 October 2000 .

0003-6935/01/122024-07\$15.00/0

(C) 2001 Optical Society of America scopy. ${ }^{7-9}$ Only a few ground-based installations that use either a polyetalon Fabry-Perot, ${ }^{10-12}$ a grating instrument, 13,14 or a Fourier-transform spectrometer (FTS) ${ }^{15}$ have an extended data record for the vertical column of $\mathrm{OH}$ that would allow the analysis of temporal variations and their relation to atmospheric chemistry.

Infrared FTS's have been used effectively for many years in atmospheric composition measurements.,5-19 Significant strides in the application of FTS's to the study of visible and near-UV spectra have been made relatively recent$1 y^{20-24}$; however, their use in atmospheric remote sensing has been limited. ${ }^{15,25,26}$ Although the FTS design suffers from a multiplex disadvantage ${ }^{20}$ compared with a grating spectrometer with an array detector when used in the UV, the combined advantages of high throughput, high spectral resolution, broad spectral coverage, and wavelength calibration stability and accuracy, ${ }^{27}$ all in a compact design, make the FTS an attractive alternative for atmospheric field measurements. For these reasons a Fourier-transform ultraviolet spectrometer (FTUVS) was developed for use in the visible and near UV to detect and quantify terrestrial atmospheric absorptions of solar radiation.

When the FTUVS is used in the direct solar imaging mode, the 27-day rotation period at the solar equator, which induces a Doppler shift (maximum $0.38 \mathrm{~cm}^{-1}$ ) in the solar spectral features at opposing solar limbs, can be utilized to discriminate the ter- 


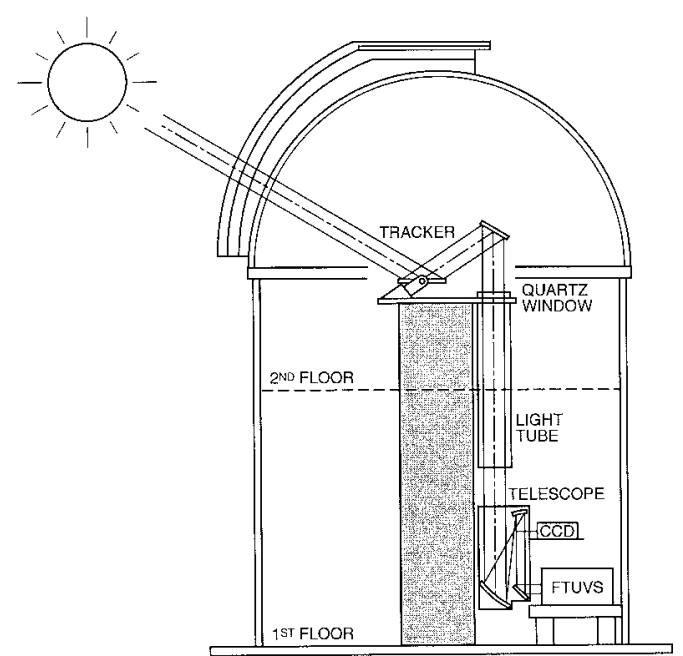

Fig. 1. FTUVS instrument system at the NASA JPL Table Mountain Facility.

restrial absorptions within the solar Fraunhofer structure. ${ }^{13,25}$ This mode places special requirements on the object tracking and imaging system that delivers light to the spectrometer.

The design of an instrument used to select and track on a solar limb, and achieve high spectral resolution to discriminate the terrestrial absorption features, is described in this paper. A demonstration of the instrument, applied to the measurement of terrestrial $\mathrm{OH}$ column abundances since July 1997, is also presented.

\section{Instrument Description}

The FTUVS system is located at the Jet Propulsion Laboratory's (JPL's) Table Mountain Facility $\left(34.4^{\circ} \mathrm{N}, 117.7^{\circ} \mathrm{W}\right.$, elevation $\left.2290 \mathrm{~m}\right)$. The instrument is comprised of the three basic subsystems as shown in Fig. 1: (1) a heliostat for tracking the Sun or Moon; (2) a beam-defining telescope with aperture and field stops, which also provides a feedback image for closed-loop tracking; and (3) an interferometer that records spectra of the selected source (Sun, Moon, or zenith sky). In addition, a data-acquisition and instrument control system allows collection and coadding of multiple scans to improve the signal-tonoise ratio (SNR).

\section{A. Heliostat}

The heliostat, constructed by DFM Engineering of Longmont, Colo., is located on the second floor of the building within the dome structure and is exposed to ambient conditions. The heliostat primary and secondary mirrors, 50.8- and 32-cm Zerodur substrates, respectively, both aluminum coated with $\mathrm{SiO}_{2}$ and $\mathrm{MgF}_{2}$ overcoats, were sized to provide an unvignetted 0.5-deg field of view and a 20-cm-diameter beam. The equatorially mounted heliostat primary mirror is driven in right ascension and declination to track any celestial object to within an accuracy of 1.8 arc sec/ min. The light beam from the heliostat passes through a 25-cm-diameter UV-grade fused silica before reaching the first-floor temperature-controlled instrument room.

\section{B. Telescope}

In the instrument room the beam passes through the telescope aperture stop before reaching the afocal Gregorian telescope primary. The telescope consists of confocal parabolic mirrors coupled to an Invar metering rod for thermal stability. The telescope offaxis parabola design is free from spherical aberration, coma, and astigmatism. The design also minimizes reflection losses by use of only two surfaces to compress the beam. The off-axis parabola telescope optics are aluminum coated, $\mathrm{SiO}_{2}$ and $\mathrm{MgF}_{2}$ overcoated, with a $\lambda / 8$ wave front.

The telescope primary is an $f / 3.2,20$-cm-diameter off-axis segment of a parabolic mirror that focuses the light beam onto a reflective, oxygen-free copper field stop. The field stop aperture allows part of the focused image to pass through to one of two telescope secondary mirrors where it is recollimated by an f/3.2, 6.4-cm-diameter parabolic mirror for delivery to the FTUVS interferometer. The rest of the image is reflected by the aluminum-coated field stop toward a $3.3-\mathrm{cm}$-diameter $f=30.5$-cm parabolic secondary. This mirror collimates the light and delivers it through neutral-density filters to a focusing lens and a CCD camera. The image is displayed on a television monitor, captured by a frame grabber board, and processed with image analysis software developed at JPL. The image position in the CCD frame is used to provide closed-loop tracking correction signals to the heliostat motor driver.

\section{Interferometer}

The collimated light beam from the telescope is directed toward the FTUVS interferometer (shown schematically in Fig. 2). The FTUVS was designed and built at the JPL. It is a flex-pivot-supported, voice-coil-actuated, active-aligned plane mirror interferometer with an etendue of $2 \times 10^{-4} \mathrm{~cm}^{2} \mathrm{sr}^{28}$ Plane mirrors were chosen to minimize the number of reflections and reduce wave-front distortion. The interferometer moving mirror mechanism is a parallelogram consisting of four tubes constructed from 152- $\mu \mathrm{m}$-thick rolled Invar for thermal and mechanical stability, connected by eight Bendix flex pivots. The lower, horizontal side of the parallelogram supports a mirror. This arm of the parallelogram is driven by a voice coil actuator along an essentially frictionless porch swing path moving the mirror horizontally $5 \mathrm{~cm}$.

The mirror is moved at a constant velocity $( \pm 0.15 \%$ rms) by a Hewlett-Packard (HP) Model 5507A laser positioning system servo-axis driver. This system uses a 2.1-MHz Zeeman split, linearly polarized, twofrequency $\mathrm{He}-\mathrm{Ne}$ laser. The polarized beams are split one each into the two interferometer arms by a small polarizing spot coating on the beam-splitter front surface. The Doppler-shifted frequency of the beam from the moving mirror arm is compared with 


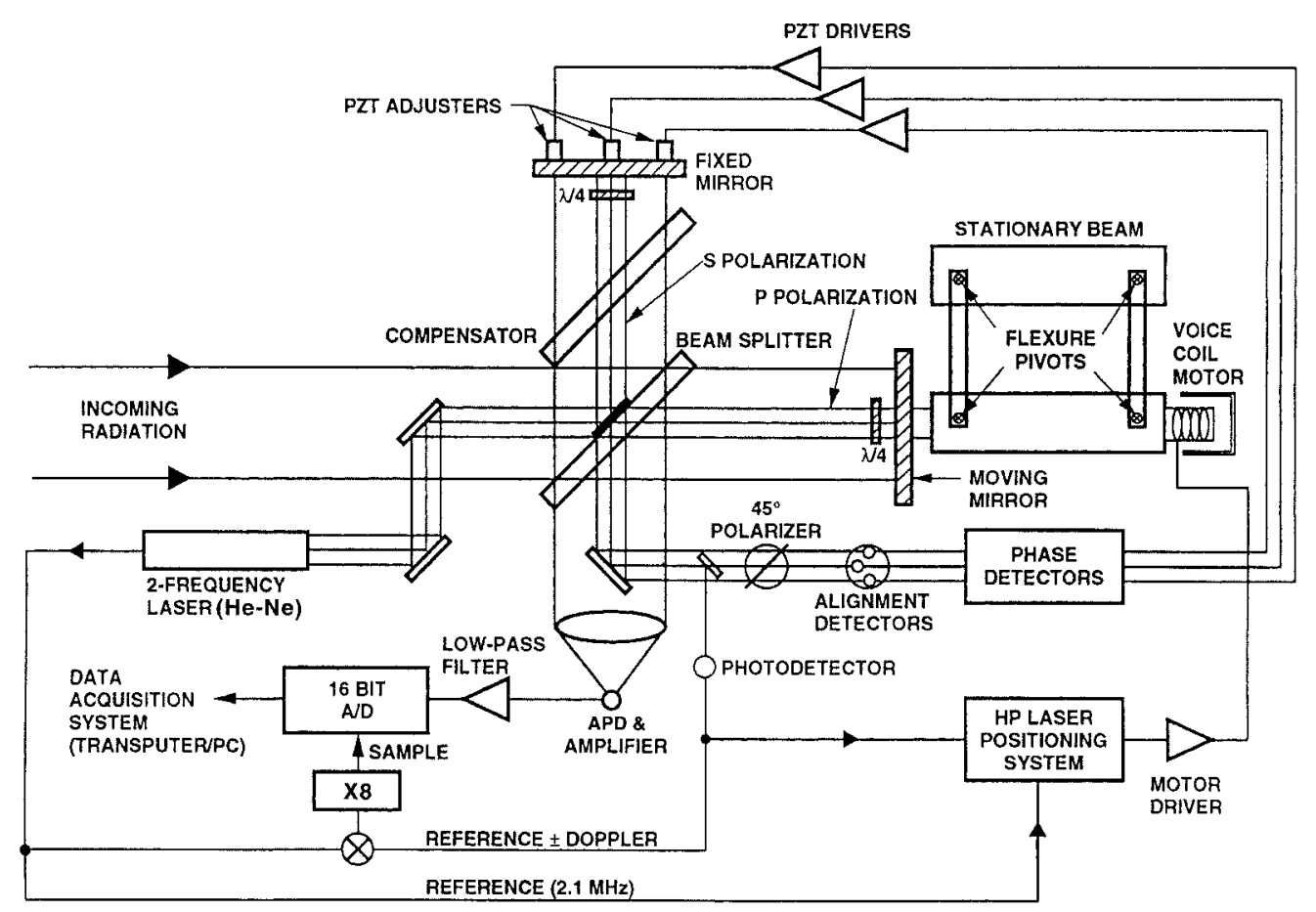

Fig. 2. FTUVS interferometer subsystem schematic. PZT, piezoelectric transducer; A/D, analog to digital converter; APD, avalanche photodiode.

the laser reference frequency for measurement and control of the scan mirror velocity. We also use the $\mathrm{He}-\mathrm{Ne}$ beam to produce an interferogram sampling trigger signal by mixing the $2.1-\mathrm{MHz}$ Zeeman split laser reference frequency with the Doppler-shifted moving mirror arm laser frequency to produce a laser fringe marker.

The intrinsic mechanical alignment accuracy of this system is better than $1 \mu \mathrm{rad}$ over $1 \mathrm{~cm}$ of travel. To achieve the desired mirror tilt stability of 0.1 urad over $5 \mathrm{~cm}$ of mechanical travel (to maintain high fringe contrast at high spectral resolution), an active tilt compensation system was added by use of a servo-controlled, piezoelectric actuator driving the fixed mirror to match the moving mirror tilt. ${ }^{29}$ The servo is activated by three miniature p-i-n photodiodes sensing the phase of the 6-mm-diameter $\mathrm{HP}$ laser positioning system $\mathrm{He}-\mathrm{Ne}$ laser reference beam at three places in the beam. A phase comparator determines the phase mismatch and produces the voltage that is required to drive the three piezostacks behind the fixed mirror to null the phase mismatch. The advantage of a heterodyne (Zeeman) laser system over a dc system employed in some commercial FTS designs is that alignment lock can be achieved and maintained without mechanical dithering, which is required to produce fringes.

Optics for the interferometer, beam splitter, compensator, and mirror substrates were figured by IC Optical of Great Britain. Coatings on the interferometer mirrors are aluminum with a $\mathrm{SiO}_{2}$ over- coat. The interferometer beam splitter has a multilayer dielectric coating, applied by Barr Associates, Inc., with 30-50\% reflectivity and 250-650 $\mathrm{nm}$ at a 45 -deg incidence angle. The beam splitter also has a central spot coating that divides the two orthogonally polarized components of the $\mathrm{He}-\mathrm{Ne}$ reference laser into the two arms of the interferometer.

For measurements of the $\mathrm{OH}$ column abundance, a narrow-bandpass interference filter, $75 \mathrm{~mm}$ in diameter, is placed at the entrance to the interferometer. Its bandpass is centered at $307.8 \mathrm{~nm}$ where the peak transmission is $45 \%$. The full-width at halfmaximum (FWHM) of this filter is $3.8 \mathrm{~nm}$, and outof-band rejection is greater than $10^{-7}$. The filter is used to isolate the strongest $\mathrm{OH}$ rotational absorption lines in the $(0,0)$ vibrational band, $X^{2} \Pi \rightarrow A^{2} \Sigma$ electronic transition.

The detector is a 5-mm-diameter UV-enhanced avalanche photodiode with a quantum efficiency of greater than 6\% in the UV and a current gain of 150 . The FTUVS instrument system has been operated successfully from 290 to $675 \mathrm{~nm}$.

\section{Data System}

In digitizing the signal, it is necessary to subdivide the laser fringes because the $\mathrm{OH}$ lines are at a wave number close to a multiple of the laser wave number. It is therefore not possible to use an electronic bandpass filter to isolate one laser frequency alias (of a width of $7899 \mathrm{~cm}^{-1}$ ) and sample it simply with the laser fringes. To accomplish the subdivision of laser 

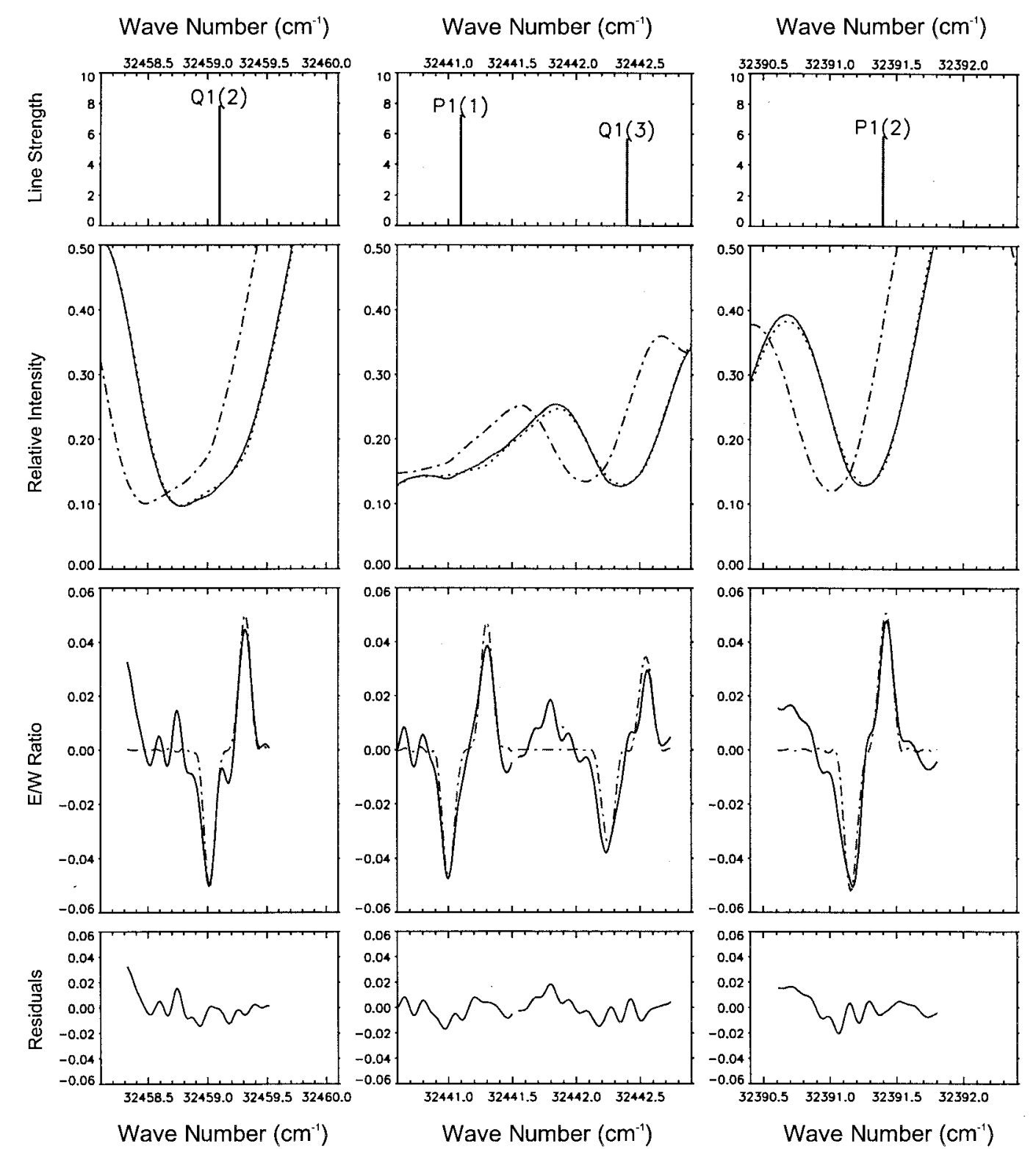

Fig. 3. Spectral retrieval of terrestrial $\mathrm{OH}$ lines by use of solar Doppler differencing: top row, positions and relative intensities of strong $\mathrm{OH}$ lines; second row, west solar limb spectrum (dot-dash curve), east spectrum (solid curve), and shifted west spectrum (dotted curve); third row, ratio spectra (solid curve) and fitted $\mathrm{OH}$ reference spectra (dot-dash curve); bottom row, residuals after fit of observed lines.

fringes, we used an analog phase-locked loop. The voltage-controlled oscillator of the phase-locked loop was selected for its low jitter noise. The laser fringe phase detector has two symmetrical outputs and was implemented in a fast integrated circuit to react to errors of the order of a few nanoseconds. A $125-\mathrm{Hz}$ active filter with differential inputs is used to reject the frequency of the laser zero crossings, which is typically in the $6-12-\mathrm{kHz}$ range. In addition, the offset of this active filter was nulled to avoid a static phase error when the circuit is fed with a constant frequency. This reduces phase detector outputs in the constant velocity mode of operation. The resulting digitized raw interferogram data are recorded to a large hard disk. The system can sustain data rates up to $10^{5}$ samples/s, at 2 bytes/sample.

\section{E. Data Reduction}

The instrument produces nearly single-sided interferograms that are individually phase corrected ${ }^{30}$ and Fourier transformed. These spectra are then averaged for the desired period of measurement. For the $\mathrm{OH}$ column observations, spectra are collected over a 15-min period at each solar limb. These summed east and west limb solar spectra are interpolated on a finer grid when the spectrum is convolved with a sinc function of a width determined by the instrument scan parameters. The necessary spectral shift (approximately $0.28 \mathrm{~cm}^{-1}$ ) to be applied to the west limb data to match the solar Fraunhofer features of the east limb spectrum is determined by minimization of the residuals in a linear- least- 


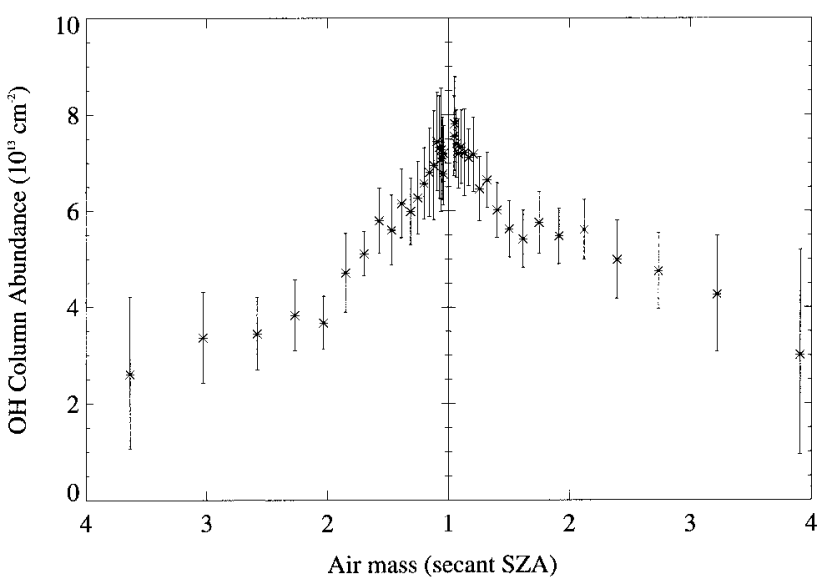

Fig. 4. Diurnal $\mathrm{OH}$ column abundance versus air mass measured on 11 May 2000, plotted out to four air masses. Vertical bars represent the $\pm 1 \sigma$ statistical error in the fitted $\mathrm{OH}$ column. Points are plotted at the average value in the range of air masses during a 15-min integration period. This range increases with increasing air mass. SZA, solar zenith angle.

squares matching of the two spectra (see Fig. 3). The east limb spectrum is then divided by the shifted west limb spectrum. The terrestrial $\mathrm{OH}$ absorption feature appears in the ratio as either a reduction in the ratio (terrestrial $\mathrm{OH}$ absorption in the east limb spectrum divided by the west limb solar background) or as an increase in the ratio (east limb background divided by $\mathrm{OH}$ absorption in the west limb spectrum). The residual baseline slope is then removed, and the absorption signatures of five to seven $\mathrm{OH}$ absorption lines are fitted to a synthetic Doppler line shape for $\mathrm{OH}$ at $250 \mathrm{~K}$, convolved with the instrument line shape. This average $\mathrm{OH}$ column temperature of 250 $\mathrm{K}$ was chosen based on a calculated $\mathrm{OH}$ densityweighted model of the temperature profile. ${ }^{31}$ Temperature sensitivity studies of the integrated $\mathrm{OH}$ line absorption cross sections ${ }^{32,33}$ demonstrated that the retrieved column abundance varied only $\pm 7 \%$ for a $\pm 30 \mathrm{~K}$ temperature change of approximately $250 \mathrm{~K}$. The synthetic $\mathrm{OH}$ absorption line fit is adjusted to minimize the square deviation between the fit and the measured $\mathrm{OH}$ feature. The resulting measured line intensity and the calculated absorption cross section of the line are then used to determine the slant column of $\mathrm{OH}$. We convert this to vertical column abundance by dividing the slant column by the air mass (approximately the secant of the solar zenith angle). Observations are obtained for air masses up to five (object zenith angles of $78 \mathrm{deg}$ ). Below this air mass, refraction has an insignificant effect on the slant column path length.

\section{Results}

The derived $\mathrm{OH}$ column is obtained from a weighted average, proportional to the line strength, of the strongest $\mathrm{OH}$ absorption lines. Over $180 \mathrm{OH}$ diurnal column data sets were acquired beginning in July 1997 for solar zenith angles of 10-78 deg (air masses of 1.02-5.0). Figure 4 presents a single day of the measured $\mathrm{OH}$ vertical column and its diurnal variation (local noon is near the center of the figure). Each point is derived from sequential 15-min integrations near the solar west and east limbs. Forty spectra are acquired, summed, and averaged to create each 15-min integrated data set. The SNR at local noon in these integrations, as measured by the $\pm 1 \sigma$ noise level outside the bandpass of the optical filter, is approximately 1700:1 under clear-sky conditions (minimal source noise contribution from haze or clouds). For the case of FTUVS, where the noise contribution from the detector and from instrument emission is negligible, the theoretical SNR is given by $^{34}$

$$
\mathrm{SNR}=\delta \bar{\nu} \Phi\left(\frac{N t}{\Delta \bar{\nu}}\right)^{1 / 2},
$$

where $\delta \bar{v}$ is the spectral resolution of $0.06 \mathrm{~cm}^{-1}, \Phi$ is the modulation efficiency of $0.6, N$ is the number of signal electrons of $1.5 \times 10^{9} \mathrm{~s}^{-1}\left(\mathrm{~cm}^{-1}\right)^{-1}, t$ is the total integration time per interferogram of $22 \mathrm{~s}$, and $\Delta \bar{\nu}$ is the width of the band-limiting filter of $400 \mathrm{~cm}^{-1}$.

The value computed by the above expression yields a SNR of 1752, which agrees closely with the measured value.

The residuals from fits to the east/west ratio spectra exhibit features that are larger than the measured photon noise (Fig. 4). These features have also been observed in previous $\mathrm{OH}$ column abundance studies that used both grating ${ }^{13,14}$ and FTS's. ${ }^{15,25}$ The observed features could be attributable to spatial inhomogeneity in the solar emission spectra from the east and west solar limbs. Alternatively, the features could arise from timedependent artifacts from the interferometer itself. Artifacts can result from coherent phase errors that occur at optical path differences that are not captured by the phase correction algorithm. These would include imperfect operation of the active alignment system, the shear motion combined with imperfect flatness of the moving mirror, and density fluctuations in the instrument associated with air currents.

In Fig. 4, vertical bars represent the change in the calculated $\mathrm{OH}$ column abundance that is produced by a 5\% change in the $\chi^{2}$ minimization when the synthetic spectra are matched to measured $\mathrm{OH}$ features. This is an indication of the measurement precision. For the data collected from November 1998 to June 2000 , the median uncertainty on the fit by use of the $Q 1(2)$ line was $\pm 18 \%$, and the median uncertainty on the fit by use of the $P 1(1)$ line was $\pm 15 \%$.

We can obtain an upper limit on the uncertainty for the accuracy of the measurement by considering measurements collected on subsequent days at nearly the same solar zenith angle. The median standard deviation scatter of measurements at nearly the same solar zenith angle is $\pm 15 \%$ when the column abundances collected from November 1998 to June 2000 for the strongest absorption lines are averaged. The range of the standard deviation is $10-22 \%$, depending on the solar zenith angle. A more rigorous anal- 


\begin{tabular}{|c|c|c|}
\hline Error Sources & $\begin{array}{l}\text { Estimate } \\
\qquad(\%)\end{array}$ & Description \\
\hline \multicolumn{3}{|l|}{ Systematic } \\
\hline \multirow[t]{2}{*}{ Line center cross section } & \pm 10 & OH vibrational level measured lifetime uncertainty. \\
\hline & \pm 7 & Stratospheric temperature uncertainty in column. \\
\hline Other absorptions & $?$ & Possible unidentified absorption features at the location of $\mathrm{OH}$ lines. \\
\hline \multicolumn{3}{|l|}{ Random } \\
\hline Spectral distortions & \pm 10 & Instrument stability, air currents, acoustic and electronic noise. \\
\hline Photon noise & \pm 2 & Poisson counting statistics. \\
\hline Pointing system & \pm 10 & $\begin{array}{l}\text { Positioning drift on Sun. Spectrum Doppler shift changes. Inte- } \\
\text { grated solar spectrum shape affected. }\end{array}$ \\
\hline $\begin{array}{l}\text { Constraining the fit } \\
\text { (least-squares } \chi^{2} \text { optimization) }\end{array}$ & \pm 15 & $\begin{array}{l}\text { Match observed spectra with modeled line shape. Residuals as- } \\
\text { sessed with a } 5 \% \text { variation about the } \chi^{2} \text { minimum. }\end{array}$ \\
\hline Total & \pm 22 & Accuracy \\
\hline
\end{tabular}

ysis of the entire data set, observation precision, and comparison with the modeled $\mathrm{OH}$ profile is in preparation. ${ }^{35}$ The sources of these uncertainties, both systematic and random, are summarized in Table 1.

\section{Summary}

We have demonstrated a compact, high-resolution, actively aligned FTS for UV-visible atmospheric spectroscopy and have applied it to the measurement of $\mathrm{OH}$ column abundances. Design of the FTUVS, with emphasis on high throughput and the retrieval of multiple $\mathrm{OH}$ spectral lines, has resulted in a data record with higher temporal resolution and precision than any obtained previously. The small footprint of the instrument and its all-flexure design are compatible with future space flight applications aimed at high-resolution UV-visible spectroscopy of Earth and planetary atmospheres. Measurements of the $\mathrm{OH}$ column are being used to validate modeled stratospheric chemistry, including seasonal variability of $\mathrm{OH}$ related to satellite and ground-based measurements of upperatmospheric ozone and water vapor, ${ }^{34}$ as well as the short time-scale effects of solar coupling, dynamics, and related chemistry.

Analysis of similar terrestrial atmospheric column data sets for $\mathrm{NO}_{3}, \mathrm{NO}_{2}$, and $\mathrm{O}_{3}$ observed with the FTUVS instrument with the following instrument operation modes are under way: (1) full disk lunar observations at $15,106 \mathrm{~cm}^{-1}(662 \mathrm{~nm})$ for nighttime abundances of $\mathrm{NO}_{3}$, (2) zenith sky observations of multiply scattered sunlight for the detection of $\mathrm{O}_{3}$ and $\mathrm{NO}_{2}$, and (3) direct solar observations for the detection of $\mathrm{NO}_{2}$.

The capabilities of this instrument will be exercised in an attempt to measure other atmospheric free radicals, including $\mathrm{BrO}$, IO, and OCIO, exploiting the broad spectral coverage and high resolution of this instrument. The FTUVS is colocated at the JPL Table Mountain Facility with several other instruments to investigate changes in, and the interactions of, $\mathrm{HO}_{x}, \mathrm{NO}_{x}$, and $\mathrm{ClO}_{x}$ families with ozone. Results from this complementary set of measurements are being analyzed to enable critical comparisons be- tween observed and modeled ozone depletion and stratospheric change.

The research described in this paper was conducted at the JPL, California Institute of Technology. It was supported by grants from the NASA Upper Atmosphere Research Program, the U.S. Naval Research Laboratory, and by the JPL Director's Discretionary Fund. We thank R. Beer, B. Farmer, R. Norton, R. Friedl, D. Peterson, and G. Toon of JPL and G. Wyntjes and J. Engel of Optra, Inc. for many valuable discussions. We also thank $\mathrm{D}$. Miller, J. MacConnell, G. A. Al-Jumaily, D. Natzic, J. D. Rex, R. Chave, R. Marquedant, J. Voeltz, and B. Wilson for their assistance with the instrument design and fabrication.

\section{References}

1. P. O. Wennberg, R. C. Cohen, N. L. Hazen, L. B. Lapson, N. T. Allen, T. F. Hanisco, J. F. Oliver, N. W. Lanham, J. N. Demusz, and J. G. Anderson, "Aircraft-borne, laser-induced fluorescence instrument for the in-situ detection of hydroxyl and hydroperoxyl radicals," Rev. Sci. Instrum. 65, 1858-1876 (1994).

2. R. M. Stimpfle, P. O. Wennberg, L. B. Lapson, and J. G. Anderson, "Simultaneous, in situ measurements of $\mathrm{OH}$ and $\mathrm{HO}_{2}$ in the stratosphere," Geophys. Res. Lett. 17, 1905-1908 (1990).

3. H. M. Pickett and D. B. Peterson, "Stratospheric OH measurements with a far-infrared limb sounding spectrometer," J. Geophys. Res. 98, 20507-20515 (1993).

4. H. M. Pickett and D. B. Peterson, "Comparison of measured stratospheric $\mathrm{OH}$ with prediction," J. Geophys. Res. 101, 16789-16796 (1996)

5. W. A. Traub, K. V. Chance, D. G. Johnson, and K. W. Jucks, "Stratospheric spectroscopy with the far-infrared spectrometer (FIRS-2)," in Remote Sensing of Atmospheric Chemistry, J. L. McElroy and R. J. McNeal, eds., Proc. SPIE 1491, 298-307 (1991).

6. D. G. Johnson, K. W. Jucks, W. A. Traub, and K. V. Chance, "Smithsonian stratospheric far-infrared spectrometer and data reduction system," J. Geophys. Res. 100, 3091-3106 (1995).

7. R. R. Conway, D. K. Prinz, and G. H. Mount, "Middle atmosphere high resolution spectrograph," in Ultraviolet Technology II, R. E. Huffman, ed., Proc. SPIE 932, 50-60 (1988).

8. R. R. Conway, M. H. Stevens, J. G. Cardon, S. E. Zasadil, C. M. Brown, J. S. Morrill, and G. H. Mount, "Satellite measure- 
ments of hydroxyl in the mesosphere," Geophys. Res. Lett. 23, 2093-2096 (1996).

9. M. F. Morgan, D. G. Torr, and M. R. Torr, "Preliminary measurements of mesospheric OH X ${ }^{2} \Pi$ by ISO on ATLAS I," Geophys. Res. Lett. 20, 511-514 (1993).

10. C. R. Burnett and E. B. Burnett, "OH PEPSIOS," Appl. Opt. 22, 2887-2892 (1983).

11. C. R. Burnett and E. B. Burnett, "Spectroscopic measurements of the vertical column abundance of hydroxyl $(\mathrm{OH})$ in the Earth's stratosphere," J. Geophys. Res. 86, 5185-5202 (1981).

12. C. R. Burnett and K. Minschwaner, "Continuing development in the regime of decreased atmospheric column OH at Fritz peak," Geophys. Res. Lett. 25, 1313-1316 (1998).

13. N. Iwagami, S. Inomata, I. Murata, and T. Ogawa, "Doppler detection of hydroxyl column abundance in the middle atmosphere," J. Atmos. Chem. 20, 1-15 (1995).

14. N. Iwagami, S. Inomata, and T. Ogawa, "Doppler detection of hydroxyl column abundance in the middle atmosphere: 2 . Measurement for three years and comparison with a 1D model," J. Atmos. Chem. 29, 195-216 (1998).

15. J. Notholt, H. Schutt, and A. Keens, "Solar absorption measurements of stratospheric $\mathrm{OH}$ in the UV with a Fouriertransform spectrometer," Appl. Opt. 36, 6076-6082 (1997).

16. C. B. Farmer, "High resolution infrared spectroscopy of the Sun and the Earth's atmosphere from space," Mikrochim. Acta (Wien) III, 189-214 (1987).

17. G. C. Toon, "The JPL MkIV interferometer," Opt. Photon. News 2, 19-21 (1991).

18. A. Goldman, C. Paton-Walsh, W. Bell, G. C. Toon, J.-F. Blavier, B. Sen, M. T. Coffey, J. W. Hannigan, and W. G. Mankin, "Network for the Detection of Stratospheric Change Fourier transform infrared intercomparison at Table Mountain Facility, November, 1996," J. Geophys. Res. 104, 30281-30303 (1999).

19. R. Zander, D. H. Ehhalt, C. P. Rinsland, U. Shmidt, E. Mahieu, J. Rudolph, P. Demoulin, G. Roland, L. Delbouille, and A. J. Sauval, "Secular trend and seasonal variability of the column abundance of $\mathrm{N}_{2} \mathrm{O}$ above the Jungfraujoch station determined from solar spectra," J. Geophys. Res. 99, 16745-16756 (1994).

20. A. P. Thorne, "Fourier transform spectrometry in the ultraviolet," Anal. Chem. 63, 57A-65A (1991).

21. R. Williams, "Applications of Fourier transform spectrometry in the ultraviolet, visible, and near-IR," Appl. Spectrosc. Rev. 25, 63-79 (1989).

22. L. M. Faires, "Fourier transforms for analytic atomic spectroscopy," Anal. Chem. 58, 1023A-1034A (1986).
23. J. W. Brault, "Solar Fourier transform spectroscopy," Oss. Mem. Oss. Astrofis. Arcetri 106, 33-50 (1979).

24. S. T. Ridgway and J. W. Brault, "Astronomical Fourier transform spectroscopy revisited," Annu. Rev. Astron. Astrophys. 22, 291-317 (1984).

25. J. W. Brault, Laboratory for Atmospheric and Space Physics, University of Colorado, 1234 Innovation Drive, Boulder, Colo. (personal communication, 1992).

26. A. C. Vandaele and M. Carleer, "Development of Fourier transform spectrometry for UV-visible differential optical absorption spectroscopy measurements of tropospheric minor constituents," Appl. Opt. 38, 2630-2639 (1999).

27. J. Chamberlain, The Principles of Interferometric Spectroscopy (Wiley, Chichester, UK, 1979).

28. S. P. Sander, R. P. Cageao, and R. R. Friedl, "A compact, high resolution Michelson interferometer for atmospheric spectroscopy in the near ultraviolet," in Optical Methods in Atmospheric Chemistry, U. Platt and H. I. Schiff, eds., Proc. SPIE 1715, 15-17 (1992).

29. R. P. Walker and J. D. Rex, "Interferometer design and data handling in a high-vibration environment. Part 1: interferometer design," in Multiplex and/or High Throughput Spectroscopy, G. A. Vanasse, ed., Proc. SPIE 191, 88-91 (1979).

30. M. L. Forman, W. H. Steel, and G. A. Vanasse, "Correction of asymmetric interferograms obtained in Fourier spectroscopy," J. Opt. Soc. Am. 56, 59-63 (1966).

31. M. Allen and M. L. Delitsky, "A test of odd oxygen photochemistry using Spacelab 3 atmospheric trace molecule spectroscopy observations,” J. Geophys. Res. 96, 12883-12891 (1991).

32. H.-P. Dorn, R. Neuroth, and A. Hofzumahaus, "Investigation of $\mathrm{OH}$ absorption cross sections of rotational transitions in the $\mathrm{A}^{2} \Sigma^{+}, \mathrm{v}^{\prime}=0 \rightarrow \mathrm{X}^{2} \Pi, \mathrm{v}^{\prime \prime}=0$ band under atmospheric conditions-implications for tropospheric long-path absorption measurements," J. Geophys. Res. 100, 7397-7409 (1995).

33. R. P. Cageao, Y. L. Ha, Y. Jiang, M. F. Morgan, Y. L. Yung, and S. P. Sander, "Calculated hydroxyl $\mathrm{A}^{2} \Sigma \rightarrow \mathrm{X}^{2} \Pi(0,0)$ band emission rate factors applicable to atmospheric spectroscopy," J. Quant. Spectrosc. Radiat. Transfer 57, 703-717 (1997).

34. R. Beer, Remote Sensing by Fourier Transform Spectrometry (Wiley, New York, 1992), pp. 60-66.

35. F. P. Mills, S. P. Sander, R. P. Cageao, V. Nemtchinov, Y. Jiang, M. A. Allen, and Y. L. Yung, "OH column measurements from the JPL Table Mountain Facility and comparisons with contemporaneous, collocated measurements of $\mathrm{O}_{3}$ and $\mathrm{H}_{2} \mathrm{O}$," in preparation (2001). 